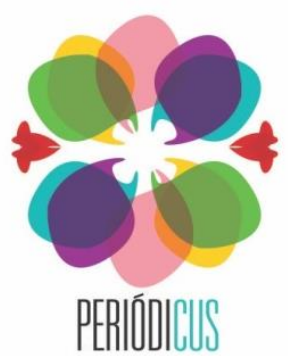

ISSN: 2358-0844

п. II, v. 2 mai. -out. 2019 р. $182-194$.

\title{
O reconhecimento
}

\section{de si de pessoas trans:}

\section{infância, sexualidade e alteridade}

\author{
Barbara de Paula Oliveira ${ }^{1}$ \\ Rosamaria Giatti Carneiro ${ }^{2}$
}

RESUMO: O reconhecimento de si de pessoas trans ocorre a partir das normas binárias de gênero mostrando que, desde a infância, há uma demanda do olhar do outro para que pessoas trans se definam dentro das normas de gênero em apenas duas possibilidades de existir. Desse modo, o presente artigo tem por objetivo descrever como as pessoas trans reconhecem a si mesmas e a sua relação com as normas binárias de gênero. Trata-se de um estudo qualitativo de cunho etnográfico, realizada no grupo de apoio a pessoas trans do Hospital Universitário de Brasília (HUB), em que, para esse trabalho, foram utilizadas as narrativas de 7 pessoas trans. Foram encontradas duas unidades temáticas em relação ao reconhecimento de si de pessoas trans: a primeira unidade mostra que, desde a infância, as pessoas trans se reconhecem como sujeitos fora das normas binárias de gênero e a segunda mostra que a sexualidade também aparece como fator importante para o reconhecimento de si. Em ambas as categorias, a alteridade se apresentou como elemento chave para o reconhecimento de si. Todos esses conflitos e necessidade de definição vêm da maneira como a sociedade lê e entende as pessoas como inteligíveis. Toda e qualquer pessoa que não se enquadrar na ideia universal de que ser mulher é ter vagina e se sentir atraída sexualmente por alguém que tem pênis será questionada e interpelada a se definir dentro de alguma das duas possibilidades para que possa existir como ser humano em nossa sociedade.

PALAVRAS-CHAVE: pessoas trans; reconhecimento de si; normas de gênero; infância.

\begin{abstract}
Self-recognition of trans persons occurs from the binary gender norms, showing that since childhood there is a demand for the other's view so that trans people define themselves within the norms of gender in only two possibilities to exist. In this way the present article aims to describe how trans people recognize themselves and their relationship with binary gender norms. This is a qualitative ethnographic study, carried out in the support group for transgender people of the University Hospital of Brasília (HUB), in which, for this work, the narratives of 7 trans persons were used. Two thematic units have been found in relation to self-recognition of trans people: the first unit shows that since childhood trans people have recognized themselves as subjects outside binary gender norms, and the second shows that sexuality also appears as an important factor for self-recognition. In both categories, alterity presented itself as a key element for self-recognition. All these conflicts and need for definition comes from the way society reads and understands people as intelligible. Anyone who does not fit into the universal idea that being a woman is having a vagina and being sexually attracted to someone who has a penis will be questioned and asked to define herself in either of the two possibilities so that she can exist as a human being in our society.

Keywords: trans people; self-recognition; gender norms; childhood.
\end{abstract}

Resumen: El reconocimiento de sí de personas trans ocurre a partir de las normas binarias de género mostrando que desde la infancia hay una demanda de la mirada del otro para que las personas trans se definan dentro de las

${ }^{1}$ Mestra pelo Programa de Pós-graduação em Ciências e Tecnologias de Saúde, da Universidade de Brasília. E-mail: barbara.7.oliveira@gmail.com

${ }^{2}$ Doutora em Ciências Sociais pela Universidade Estadual de Campinas e professora adjunta da Universidade de Brasília. E-mail: rosagiatti@yahoo.com.br 
normas de género en apenas dos posibilidades de existir. De este modo, el presente artículo tiene por objetivo describir cómo las personas trans se reconocen a sí mismas y su relación con las normas binarias de género. Se trata de un estudio cualitativo de cuño etnográfico, realizado en el grupo de apoyo a personas trans del Hospital Universitario de Brasilia (HUB), en el que, para ese trabajo, se utilizaron las narrativas de 7 personas trans. Se encontraron dos unidades temáticas en relación al reconocimiento de sí de personas trans: la primera unidad muestra que, desde la infância, las personas trans se reconocen como sujetos fuera de las normas binarias de género y la segunda muestra que la sexualidad también aparece como factor importante para el reconocimiento de sí. En ambas categorías la alteridad se presentó como elemento clave para el reconocimiento de sí. Todos estos conflictos y necesidad de definición vienen de la manera como la sociedad lee y entiende a las personas como inteligibles. Toda persona que no se encuadre en la idea universal de que ser mujer es tener vagina y sentirse atraída sexualmente por alguien que tiene pene será cuestionada e interpelada a definirse dentro de alguna de las dos posibilidades para que pueda existir como ser humano en nuestra sociedad.

Palabras clave: personas trans; reconocimiento de sí; normas de género; infancia.

ISSN: 2358-0844 п. II, v. 2 mai. -out. 2019 p. $182-194$. 


\section{Introdução}

As pessoas trans são interpeladas cotidianamente a respeitos de seus corpos, identidade e sexualidade. Isso acontece devido às normas binárias de gênero porque espera-se que, "naturalmente", todas as pessoas sejam homens/mulheres a partir de conceitos que foram socialmente construídos. Tais conceitos poderiam ser lidos como cisheteronormatividade, que dizer, trata-se de um termo usado para mostrar que existe uma norma que pressupõe a heterossexualidade e a cisgeneridade como a orientação sexual e identidade de gênero, respectivamente, "normais" dentro da nossa sociedade.

Segundo Vergueiro (2015.p.44), "o termo “cisgênero" é um conceito que abarca as pessoas que se identificam com o gênero que lhes foi determinado quando de seu nascimento, ou seja, as pessoas não-transgêneras"3. . Assim, para compreendermos como se dá o reconhecimento de si de pessoas trans seria necessário entender que existe uma naturalização de corpos binários que foram significados de acordo com discursos de poder:

\footnotetext{
Para produzir uma leitura crítica sobre a construção normativa das identidades de gênero corporificadas como algo a ser derivado (através de distintos dispositivos de poder) de um cistema 'sexo/gênero' que tem sua normalidade produzida através da naturalização da prédiscursividade, binariedade e permanência para os corpos e identidades de gênero (VERGUEIRO, 2015, p.45)
}

A normatividade de gênero e/ou cisnormatividade ou normatividade cisgênera exerce um dispositivo de poder que possui efeitos colonizadores sobre os corpos e subjetividades em diferentes formas e graus que não estejam de acordo com as ideias normativas. Ao utilizarmos o conceito de cisgeneridade conferimos complexidade a suposta naturalidade dada aos corpos cisgêneros, pois estamos conceituando o que é nascer com um determinado corpo e se identificar com ele (VERGUEIRO, 2015).

A sexualidade também é normatizada e se apresenta como um dos elementos da cisgeneridade, pois tem a heterossexualidade como seu pressuposto de normalidade. Vergueiro (2015) argumenta que a heterossexualidade como orientação sexual normal e "saudável" também é um dispositivo de poder construído como base da sociedade. Uma vez que a homossexualidade já foi considerada uma doença, a heterossexualidade carregava e ainda pressupõe que o desejo sexual "normal" é atração de homem

${ }^{3}$ No texto original, a autora escreve "pessoas não-transgêneros" (VERGUEIRO, 2015, p.44).

Periódicus, Salvador, n.11, v. 2, mai-out.2019 - Revista de estudos indisciplinares em gêneros e sexualidades Publicação periódica vinculada ao Núcleo de Pesquisa NuCuS, da Universidade Federal da Bahia - UFBA ISSN: 2358-0844 - Endereço: http://www.portalseer.ufba.br/index.php/revistaperiodicus 
cis por mulher cis e/ou de mulher trans por homens cis.

O uso do termo cisheteronormatividade é pensado por Vergueiro (2015) como consequência do que Butler (2015) coloca como subjetividades que podem ou não ser vividas. Se os corpos não binários não podem existir, por não estarem inseridos na norma, pois quebram com a linearidade pênis-homem e vagina-mulher, consequentemente, suas sexualidades também quebrarão com o esperado. Assim os sistemas não são apenas cisnormativos, mas também heteronormativos. Quando o diagnóstico médico entende que a pessoa trans procura por uma cirurgia para "corrigir" o corpo errado, esse mesmo diagnóstico prevê que tal correção será realizada para que a pessoa trans possa viver sua sexualidade de maneira heterossexual. Assim, a cisheteronormatividade se insere num pré-discurso que prevê a permanência e a binariedade do que é possível de existir e ser enxergado como ser humano na sociedade.

Esse pré-discurso cisheteronormativo também prevê uma binariedade e permanência do entendimento de si. Quer dizer, só será possível ser reconhecido dentro de duas alternativas: macho/homem e fêmea/mulher e espera-se que, ao migrar de um gênero a outro, isso ocorra de forma permanente, não havendo nuances e outras possibilidades, mas apenas uma incoerência fisiológicapsicológica que se adeque ao padrão binário. Vergueiro (2015) pondera que os elementos da cisgeneridade, a heteronormatividade, a binariedade e a permanência, afetam profundamente a vida das pessoas trans, pois suas subjetividades explodem normas e, ao acessarem os sistemas sociais, têm seus corpos interpelados e identidades questionadas.

A partir de tais conceitos, o presente artigo tem por objetivo descrever como as pessoas trans reconhecem a si mesmas e a sua relação com as normas binárias de gênero.

\section{Método}

Foi realizada uma pesquisa qualitativa de cunho etnográfico com observação participante e entrevistas semiestruturadas. Apesar de ser lida como uma metodologia de pesquisa, a etnografia extrapola os significados do que vem a ser método, não podendo ser descrita como algo que se define dentro de certas limitações, pois os caminhos para se fazer uma etnografia, sobretudo nos estudos sobre saúde, são amplos e buscam por sentidos profundos da vida das pessoas para além de sinais e sintomas de doenças e/ou diagnósticos médicos. Como coloca Peirano (2014), fazer etnografia ultrapassa qualquer definição metodológica que limite a experiência em campo. Já a observação participante é feita por meio das faculdades e habilidades do olhar, ouvir e escrever, descritos por Oliveira (1998), por meio de anotações no diário de campo e depois análise profunda das impressões, 
expressões e experiências de campo. O diário de campo é o espaço em que é anotado o que foi observado e o que foi discutido em campo para depois ser feita uma análise dos acontecimentos juntamente com as entrevistas realizadas.

A pesquisa foi realizada no grupo de apoio a pessoas trans do Hospital Universitário de Brasília (HUB-DF) durante os meses de fevereiro a agosto de 2016. Foi feita observação participante semanalmente no grupo e foram realizadas entrevistas semiestruturadas com os participantes do grupo. Trata-se da minha pesquisa de mestrado e, vale dizer, que meu lugar de fala é de uma mulher cisgênera heterossexual e branca, ou seja, quer dizer que me compreendo como mais uma pessoa que teve oportunidade para falar de algo que provavelmente eu nunca vá compreender por completo, justamente por não viver em meu corpo e/ou em minha subjetividade as violências da cisnormatividade e/ou do cissexismo. Portanto, me coloco neste trabalho em uma tentativa de falar sobre o que ouvi, vi e vivi em seis meses de convivência com pessoas trans. O termo trans foi escolhido porque o mesmo é usado por parte comunidade trans por se tratar de um termo guardachuva não-binário que abrange várias subjetividades trans.

Para o presente trabalho foram utilizadas sete narrativas de pessoas trans, nomeadas de Marta, Roberta, Pedro, Natasha, Cristina, Karen e Maya (seus nomes foram trocados para preservar suas identidades). A pesquisa foi aprovada pelo CEP-FS sob o parecer de $n^{\circ} 1395423$. Para a entrevista semiestruturada pedi aos/às participantes para me contarem um pouco sobre suas histórias de vida e questionei como aconteceu o reconhecimento de si enquanto pessoas trans. Para análise de dados, foi feita uma análise de conteúdo (BARDIN, 2011) que permitiu o agrupamento das respostas abertas das entrevistas semiestruturadas e as anotações do diário de campo em unidades temáticas.

\section{Resultados}

Durante o processo etnográfico notei que muitas pessoas trans falavam de suas histórias a partir de experiências que ocorreram ainda na infância. Por esse motivo, quando realizava as entrevistas individuais, questionava as pessoas sobre como aconteceu o reconhecimento de si enquanto pessoas trans. Assim foi possível encontrar como resultado duas unidades temáticas: a primeira unidade mostra que desde a infância as pessoas trans se reconhecem como sujeitos fora das normas binárias de gênero. A segunda unidade traz também a sexualidade como parte da quebra dessas normas, pois muitas pessoas trans se reconhecem primeiro como homossexuais para depois compreenderem que identidade de gênero e sexualidade são dimensões diferentes de suas

Periódicus, Salvador, n.11, v. 2, mai-out.2019 - Revista de estudos indisciplinares em gêneros e sexualidades Publicação periódica vinculada ao Núcleo de Pesquisa NuCuS, da Universidade Federal da Bahia - UFBA ISSN: 2358-0844 - Endereço: http://www.portalseer.ufba.br/index.php/revistaperiodicus 
subjetividades. Em ambas as categorias a alteridade se apresentou como elemento chave para o reconhecimento de si. A seguir serão discutidos os resultados encontrados.

\section{Discussão}

\subsection{O reconhecimento de si a partir da infância}

Durante o trabalho de campo, quando conversava de maneira individual com as pessoas trans, notei que todas, ao me contarem suas histórias, narravam que desde a infância percebiam não pertencer às normas de gênero. Essa percepção se dá, sobretudo, na expectativa gerada pelo órgão genital e pelos papéis de gênero socialmente construídos. Bento (2012) nos dá luz a essa questão, dizendo que, no momento da gestação, as expectativas em torno do sexo do bebê são geradas e projetadas para criança que irá nascer. A partir da constatação do órgão genital, cores, brinquedos e roupas serão escolhidos de acordo com esse órgão.

Em campo, quando pedia que me contassem suas histórias de vida, relatos como o de Pedro, Natasha e Roberta chamaram atenção quanto a força da norma social de gênero, ao notarem que não pertenciam à categoria que lhes foi atribuída ao nascer:

Desde criança você começa já a perceber que você não é igual as outras crianças. Por exemplo, é... começa nas brincadeiras né. No meu caso eu nunca quis brincar de boneca com as meninas, entendeu? Sempre fui voltado para o lado dos meninos só que na minha cabeça eu sempre fui um menino, entendeu. Eu não tinha aquela coisa ainda né, a inocência de saber como é anatomicamente. Tipo, será que eu sou menino, menina? Tipo, a criança não olha o corpo do outro, não fica analisando (Pedro)

Se eu visse uma menina de cabelo curto eu ficava revoltada. Se eu visse uma menina de cabelo curto eu achava que ela era na verdade um menino que tava com uma roupa de menina. [...] o cabelo curto quando você é criança é o que separa gênero então uma menina de cabelo curto fica com cara de menino. Então eu pensava "isso é um menino" e via de sainha e ficava revoltada. (Natasha)

Eu sempre tive esse conflito, esse conflito já veio comigo porque quando criança as pessoas olhavam pra mim e diante da minha mãe perguntavam se era menino ou menina (Roberta)

Souza (2006) coloca que as crianças aprendem sobre os papéis de gênero através da linguagem e que por ela aprendem a se comportar de maneira adequada de acordo com uma menina ou um menino. A linguagem seria uma prática social que disseminaria as normas de gênero na medida em 
que dita o que é ser menino/menina ainda na infância. Assim, as crianças vão assimilando o que lhes é colocado através das linguagens verbais e não-verbais e aprendendo o que é esperado delas de acordo com o órgão genital.

Nas três narrativas nota-se o discurso do que é masculino e feminino e, mesmo sem ter com o que comparar, já existe no imaginário da criança o que determina o que cada um é. Para Pedro, a feminilidade estava nas brincadeiras de boneca e a masculinidade no não interesse por isso. Para Natasha, estava no tamanho do cabelo, pois enxergava incoerência entre cabelos curtos e ser feminina. Já para Roberta, temos a dimensão do olhar do outro exigindo o que será definido para aquele corpo. Roberta não explica por que as pessoas não conseguiam distinguir ela de um homem/mulher, mas vemos que, mesmo ela não compreendendo por que não conseguiam definir a qual gênero ela pertencia, a exigência do outro a fez perceber que ela não estava dentro da norma.

O discurso cisheteronormativo está tão bem construído nessa dicotomia homem-pênis-carrinho e mulher-vagina-boneca que, "naturalmente", Pedro, Natasha e Roberta relatam terem se sentido diferentes por não se encaixarem nessa lógica. Relatam que suas percepções remontam à infância, pois desde esse período é possível sentir a norma manifestada em seus corpos e brincadeiras. Sabemos que os jogos e brincadeiras não determinam quem somos necessariamente, mas questionamos e desenhamos nossas brincadeiras, nossas roupas e nossos cortes de cabelo a partir da matriz binária heteronormativa - essa sim que nos desenharia. Fazemos associações de sexualidade e gênero ainda na infância por acreditarmos que isso poderia dizer algo sobre nós mesmos/as. Mas será que diz ou apenas nos mostra a hegemonia da construção cisheteronormativa sobre nós e os que nos cercam?

Laraia (2001) propõe pensar ainda o conceito de cultura nas diferenciações que fazemos das pessoas. O autor diz que tendemos a excluir e marginalizar as pessoas que não se adequam aos valores preponderantes dentro de nossa cultura. Cita, inclusive, o exemplo das pessoas homossexuais que foram e ainda são excluídas em nossa cultura por serem consideradas fora dos padrões heterossexuais. A cultura nos ensina os significados em torno do nosso corpo. De acordo com Laraia (2001), é a cultura que vai modificar o biológico e colocar funções em cada corpo de acordo com o sexo, como, por exemplo, é ensinado às pessoas que nascem com vagina, desde a infância, a se portarem, caminharem e sentarem de uma maneira diferente das pessoas que nascem com pênis. E assim as definições do que viria a "ser mulher/homem" surgem e geram uma expectativa nos corpos que foram definidos como masculino/feminino desde a gestação. Trata-se de uma cultura ocidental que foi construída em cima de valores cisheteronormativos que pressupõe definições universais para o que é ser homem e mulher a 
partir da biologia e, portanto, propagará esses valores de maneira a normatizar os corpos.

Lanz (2014) traz ainda a intolerância que os ambientes familiares e escolares desencadeiam quando papéis ditos masculinos/femininos não são cumpridos, mostrando a naturalidade ou imposição da associação entre o que se tem como masculino/feminino com o órgão genital. Como o relato de Cristina, que diz ter se percebido diferente desde a infância, mas que não compreendia os modos como a chamavam de modo ofensivo:

E eu acho que que tava na $1^{\circ}$ série... 6, 7 anos. Mas já sabia, eu não sabia dos xingamentos que as pessoas usavam na escola, não sabia nem por quê e depois que eu fui me questionando por ser diferente né. (Cristina)

Por outro lado, podemos pensar o reconhecimento de si, ainda na infância, partindo do conflito relatado por Roberta, em que houve uma exigência de nomeação sobre o que ela era, se era menino ou menina. Vemos aqui que o ato "relatar a si mesmo", pensado por Butler (2015, p.18), se dá em uma troca com o outro e que não podemos existir por existir, precisamos nos relatar para existir e esse relato, esse reconhecimento de si, está inserido nas normas vigentes.

O "eu" não se separa da matriz prevalecente das normas éticas e dos referenciais morais conflituosos. Em um sentido importante, essa matriz também é a condição para o surgimento do "eu", mesmo que o "eu" não seja induzido por essas normas em termos causais. Não podemos concluir que o "eu" seja simplesmente o efeito ou o instrumento de algum éthos prévio ou de algum campo de normas conflituosas ou descontínuas. Quando o "eu" busca fazer um relato de si mesmo, pode começar consigo, mas descobrirá que esse "si mesmo" já está implicado numa temporalidade social que excede suas próprias capacidades de narração; na verdade, quando o "eu" busca fazer um relato de si mesmo sem deixar de incluir as condições de seu próprio surgimento, deve, por necessidade, tornar-se um teórico social (BUTLER, 2015, p.18).

Não haveria como Pedro, Natasha e Roberta fazerem um relato de si desde a infância sem pensar que, mesmo se sentindo homem/mulher, o que estava exterior, ou seja, o que é "ser homem/mulher" pela cisheteronormatividade, estava dizendo a eles/as que esse sentimento, por si só, não os definiria como tais. Já que, antes do reconhecimento de si como homem/mulher, existe uma narrativa social histórica e cultural do que é ser homem/mulher. A percepção vem do desencaixe dessa narrativa.

\subsection{A sexualidade como reconhecimento de si}

Além dos papéis de gênero, confrontados ainda na infầncia, a sexualidade é outra dimensão que,

Periódicus, Salvador, n.11, v. 2, mai-out.2019 - Revista de estudos indisciplinares em gêneros e sexualidades Publicação periódica vinculada ao Núcleo de Pesquisa NuCuS, da Universidade Federal da Bahia - UFBA ISSN: 2358-0844 - Endereço: http://www.portalseer.ufba.br/index.php/revistaperiodicus 
para o reconhecimento de si, serve como norteadora daquilo que "eu sou" e daquilo que "eu não sou". Embora saibamos que a sexualidade não é necessariamente definidora de subjetividades, ela ainda aparece como um artifício para delimitar supostas identidades calcada na concepção de que somos apenas um único ser sem nuances. Todas as pessoas com as quais conversei durante a pesquisa relataram que, ao se identificarem como alguém diferente do que lhe era esperado, primeiro o faziam como homossexuais. Ou porque as outras pessoas diziam que eram homossexuais ou porque achavam que o desejo pela pessoa do mesmo sexo/gênero configurava, necessariamente, homossexualidade.

Há aqui dois pontos importantes no reconhecimento de si, tendo a homossexualidade como um primeiro ato de se reconhecer diferente do que é esperado. O primeiro é o ato de "relatar a si mesmo" feito a partir da interpelação do outro, como também aparece nos relatos de infância. A partir do olhar cisheteronormativo, as pessoas consideram que há algo diferente nas pessoas trans, seja pelo comportamento ou pela forma de se vestir, e passam a cobrar um "relato de si mesmo" e/ou a definir o que o outro é. A homossexualidade é a primeira quebra da cisheteronormatividade, logo todo comportamento que foge da ideia binária linear (homem-pênis-desejo por mulher e mulher-vaginadesejo por homem) é associado à homossexualidade. Mesmo sabendo que a identidade de gênero não tem relação com o órgão genital necessariamente, as pessoas naturalmente fazem essa associação. Se um corpo dito masculino tem trejeitos femininos ele é associado como homossexual. Vejamos nos seguintes trechos de campo na fala de Marta e Roberta:

\footnotetext{
A primeira categoria na qual eu me identifiquei foi homossexual, gay! Porque era o que existia na época [...] Aí depois assim nas relações sexuais que depois eu comecei a perceber que assim eu não gostava que eles me tocassem né, enfim foi um conjunto de fatores e aí no final das contas eu falei "não, eu não sou homossexual, sou trans né, tá tudo errado" (risos) (Marta)
}

Eu achava que eu era gay porque na minha cidade, no interior, esse povo é assim: ou você é o homem ou a mulher ou você é o viadinho, a bicha (Roberta)

As primeiras associações são atreladas ao que é considerado anormal, ou seja, fora do heteronormativo. Quando Marta coloca "porque era o que existia na época" vemos que a homossexualidade foi a primeira categoria a quebrar com as normas, devido ao seu próprio contexto histórico de luta contra o estereótipo do HIV e os movimentos sociais em torno da despatologização da homossexualidade. De acordo com Louro (2016), a homossexualidade seria uma invenção do século XIX, momento em que as pessoas homossexuais passaram a ser vistas como um outro tipo de sujeito, fazendo-se assim uma associação entre a prática sexual e a identidade das pessoas. A partir da década de 1970, os movimentos sociais homossexuais começaram a questionar a 
heterossexualidade enquanto normalidade. Já no final da mesma década, o movimento gay e lésbico passa a se colocar como um movimento identitário em que "reconhecer-se nessa identidade era uma questão pessoal e política" (LOURO, 2016, p.32).

O segundo ponto do reconhecimento de si como homossexual vem da própria sexualidade, mas ainda inserido no pensamento cisnormativo, uma vez que a associação feita, a princípio, se dá pelo órgão genital que as pessoas possuem e não pelo gênero com o qual se identificam.

Com 16 anos eu me assumi como gay pra ficar mais fácil. Porque ai as pessoas não iam me empurrar pra ter uma relação com uma mulher que era o que eu não me identificava. Só que eu ainda me sentia triste. Eu não queria viver como um gay. (Cristina)

Depois de um certo tempo eu me identifiquei como homossexual. Eu gostava de homem. Mas de outro certo tempo eu percebi que eu não era um homem que gostava de homem, mas uma mulher que gostava de homem. E por isso eu me identifiquei como transexual. Transexual pelo fato de eu ter a identidade de gênero feminina, me entender como mulher, me visualizar como mulher e ainda ter um corpo feminino. (Karen)

Eu sabia que eu era diferente dos homossexuais. Aí eu comecei amizade com homossexuais, com as lésbicas e os gays. Foi quando começou a vida amorosa. Comecei a namorar com menina. E as meninas, eu ficava sempre assim "cara, por que que toda vez que eu namoro com uma menina a gente termina e ela vai namorar com homem?" Toda vez, toda vez, eu sou a cura gay saca? (risos) Todas as minhas ex-namoradas que diziam ser lésbicas hoje são hetero e tem filhos. (Pedro)

Nas narrativas de Cristina, Karen e Pedro vemos que o "se identificar" como homossexual está numa relação direta de "nasci com pênis e me sinto atraída por homens, logo sou gay". Ou então, "nasci com vagina e me sinto atraída por mulheres, logo sou lésbica". Entretanto, tais ideias parecem não bastar, pois o conflito continua existindo, uma vez que sentem ainda que somente aquilo (a dimensão biológica) não é capaz de delimitar quem são. Não se sentem homens/mulheres de acordo com o órgão genital e, mais tarde, passam a perceber que não são homossexuais, mas transexuais por perceberem que suas identidades de gênero não estão associadas com seus órgãos biológicos, mas com a maneira como se compreendem enquanto homens e mulheres.

É interessante notar a curiosa associação que Pedro faz sobre suas ex-namoradas. Elas terminam o relacionamento com ele para namorarem homens cisgêneros e ele interpreta isso como se essas garotas, na verdade, gostassem de homem e não de mulher, pois quando namoravam com ele, ele ainda não havia feito a "transição corporal". Consequentemente, para ele, esse desejo que 
suas ex-namoradas têm por homens cisgêneros e, ao mesmo tempo, o fato de terem se relacionado com ele, demonstrava que ele também era um homem e não uma mulher. Vemos aqui novamente o outro sendo parte do processo do reconhecimento de si mesmo. A relação de Pedro com outras pessoas o fez pensar sobre quem ele era.

Esses relatos ainda estão, numa certa medida, dentro do esperado pois, uma vez que se identificam como pessoas trans, é como se o "problema" estivesse resolvido, já que, ao pesquisarem sobre o assunto e descobrirem o termo transexual, se encaixam na dimensão reconhecida pela medicina: “pessoa que nasceu no corpo errado". O entendimento médico da transexualidade é de que as pessoas trans são naturalmente heterossexuais e cis, que nasceram com o órgão errado no corpo errado. Quando se faz um diagnóstico de “disforia de gênero" pressupõe-se que a pessoa trans odeie seus órgãos genitais e que querem retirá-lo, para viverem suas sexualidades de maneira heterossexual. Ou seja, retirar o pênis para pôr uma vagina e ser penetrada por um pênis (o mesmo pensamento se encaixa para homens trans). Isso não é de todo falso, já que há de fato pessoas trans com esse desejo, porém não é uma verdade absoluta para todas. Como bem nos conta, por exemplo, Maya:

Eu comecei a tomar aquela imagem pra mim que eu era gay, pra mim eu era gay e era gay e pronto. Todo mundo me chamava de gay e eu atribuía aquilo pra mim. Mais tarde, lá por volta de 12, 13 anos de idade, que eu acho que é a idade que a gente mais começa a sentir as atrações sexuais né, eu comecei a me sentir atraída por meninas e aquilo me bagunçou, eu falei "véi, mas se eu sou gay como que gosto de menina sabe” (Maya)

Maya passa a se reconhecer como gay por causa do olhar do outro, mas o "ser gay" até o momento de descoberta da sua sexualidade não tinha nenhuma relação com seus desejos sexuais, mas como uma imagem feita por associação entre a maneira como ela se vestia e se portava considerada feminina num corpo dito masculino. Para piorar o entendimento de si dentro da norma, Maya passa a viver um conflito ainda maior. Nasceu com órgãos sexuais ditos masculinos, a tacharam como gay e, mais tarde, percebe se sentir atraída por mulheres, automaticamente a associação que faz é “se eu sou gay como posso gostar de meninas?”. Maya sabia que queria ser menina e quando descobriu o termo transexual se identificou, mas o conflito com seu desejo sexual voltou a pôr em questão sua subjetividade.

Eu quero ser menina, como que eu faço pra ser menina? Ai foi que eu descobri o termo transexual e ai que eu me defini como trans. Quero ser menina, gosto de meninas e eu sou trans, gosto de meninas e aquilo fez uma bagunça enorme na minha cabeça. [...] Esse fato de eu descobrir que gosto de meninas fez uma bagunça muito grande na minha vida porque aí eu 
coloquei na minha cabeça que eu era homem, que eu tinha que ser homem porque eu gostava de meninas então eu tinha que ser homem (Maya)

A confusão na cabeça de Maya reforça o impacto do discurso binário heteronormativo existente em nossa sociedade. Na década de 1980, Rich (1980) declarou que nossa sociedade se fundamentaria numa "heterossexualidade compulsória", querendo dizer que a heterossexualidade nunca seria questionada na nossa sociedade, acreditando-se que seria o natural e as outras manifestações, tanto de prática como de orientação sexual, seriam as não naturais ou anormais. A espera natural de que o feminino deve se sentir atraído pelo masculino atravessa Maya ao se constituir enquanto indivíduo. Uma vez que se identificou como mulher e não se sentiu atraída por homens, isso causou um estranhamento e fez com que ela procurasse outras maneiras de se identificar.

Maya é uma mulher trans lésbica, mas a cisheteronormatividade não lhe permitia reconhecer isso, suas associações ainda eram realizadas dentro da norma: se nasci com pênis e desejo mulheres, como que sou gay? Mas, ao mesmo tempo, seu conflito continua por não se identificar como homem. Vemos em Maya a descontinuação do homem-pênis-desejo por mulher, já que ela se identifica como mulher, deseja ter uma vagina (ela fez cirurgia) e se sente atraída por mulheres. Se pensarmos na ideia de linearidade, Maya é uma mulher-vagina-desejo por mulher. Ela vai de encontro com todos os critérios e diagnósticos da medicina e com a cisheteronormatividade.

\section{Considerações finais}

A partir dos relatos de campo foi possível notar alguns aspectos do reconhecimento de si pelas pessoas trans. Vemos que, desde a infância, seus corpos e subjetividades são interpelados pelo olhar do outro numa tentativa de definição de quem são. As normas binárias de gênero, vigentes em nossa sociedade, atravessam sobretudo as pessoas trans por marcarem nossos corpos de maneira linear não permitindo outros entendimentos de si mesmos para além dos estereótipos menina-cor rosa-brincar de boneca, por exemplo, ainda na infância. Mais tarde, quando a dimensão da sexualidade aparece, novos estereótipos são colocados e novamente as pessoas trans se veem num conflito de definição de si mesmas. Todos esses conflitos e necessidade de definição vem da maneira como a sociedade lê e entende as pessoas como inteligíveis. Toda e qualquer pessoa que não se enquadrar na ideia universal de que ser mulher é ter vagina e se sentir atraída sexualmente por alguém que tem pênis, será questionada e interpelada a se definir dentro de alguma das duas possibilidades para que possa existir como ser humano em nossa sociedade.

Periódicus, Salvador, n.11, v. 2, mai-out.2019 - Revista de estudos indisciplinares em gêneros e sexualidades Publicação periódica vinculada ao Núcleo de Pesquisa NuCuS, da Universidade Federal da Bahia - UFBA ISSN: 2358-0844 - Endereço: http://www.portalseer.ufba.br/index.php/revistaperiodicus 


\section{Referências}

BARDIN, Laurence. Análise de conteúdo. Lisboa: Edições 70, 2011.

BENTO, Berenice. O que é transexualidade? 2. ed. São Paulo: Brasiliense, 2012.

BUTLER, Judith. Problemas de gênero: feminismo e subversão da identidade. 8. ed. Rio de Janeiro: Editora Civilização Brasileira, 2015a.

BUTLER, Judith. Relatar a si mesmo. Crítica da violência ética. Belo Horizonte: Autêntica, 2015b.

LANZ, Letícia. O corpo da roupa - A pessoa transgênera entre a transgressão e a conformidade com as normas de gênero. 2014. Dissertação (Mestrado em Sociologia). Curso de Pós-Graduação em Sociologia. Universidade Federal do Paraná, Curitiba. 2014.

LARAIA, Roque de Barros. Cultura. Um conceito antropológico. 14. ed. Rio de Janeiro: Jorge Zahar Ed, 2001.

LOURO, Guacira Lopes. Um corpo estranho. Ensaios sobre sexualidade e teoria queer. 2. ed. Belo horizonte: Autêntica, 2016.

$\mathrm{RICH}$, Adrienne. Compulsory heterosexuality and lesbian experience. Signs. Women: sex and sexuality, v. 5, n. 4, p. 631-660, 1980.

OLIVEIRA, Roberto Cardoso de. O trabalho do antropólogo. Brasília/São Paulo: Paralelo Quinze/Editora da Unesp, 1998.

PEIRANO, Mariza. Etnografia não é método. Horizontes Antropológicos. Porto Alegre, ano 20, n. 42, p. 377-391. 2014.

SOUZA, Érica Renata de. Marcadores sociais da diferença e infância: relações de poder no contexto escolar. Cadernos Pagu, n. 26, p. 169-199, 2006.

VERGUEIRO, Viviane Simakawa. Por inflexões decoloniais de corpos e identidades de gênero inconformes: uma análise autoetnográfica da cisgeneridade como normatividade. 2015. Dissertação (Mestrado em Cultura e Sociedade) Instituto de Humanidades, Artes e Ciências Professor Milton Santos. Universidade Federal da Bahia, Salvador. 2015. 